\title{
Effect of Metal Dopant on Ninhydrin-Organic Nonlinear Optical Single Crystals
}

\author{
R. S. Sreenivasan, ${ }^{1}$ N. Kanagathara, ${ }^{2}$ G. Ezhamani, ${ }^{3}$ N. G. Renganathan, ${ }^{4}$ and G. Anbalagan ${ }^{5}$ \\ ${ }^{1}$ Department of Chemistry, Saraswathi Velu College of Engineering, Sholinghur, Vellore 631 102, India \\ ${ }^{2}$ Department of Physics, Veltech Multi Tech Dr. Rangarajan Dr. Sakunthala Engineering College, Avadi, Chennai 600 062, India \\ ${ }^{3}$ Department of Physics, SRR Engineering College, Padur, Chennai 603 103, India \\ ${ }^{4}$ Department of Chemistry, Vel Tech Dr. RR \& Dr. SR Technical University, Chennai 600 062, India \\ ${ }^{5}$ Department of Physics, Presidency College, Chennai 600 005, India
}

Correspondence should be addressed to R. S. Sreenivasan; rssvasan1973@yahoo.co.in

Received 24 June 2012; Revised 16 September 2012; Accepted 16 September 2012

Academic Editor: Lahcen Bih

Copyright (C) 2013 R. S. Sreenivasan et al. This is an open access article distributed under the Creative Commons Attribution License, which permits unrestricted use, distribution, and reproduction in any medium, provided the original work is properly cited.

In the present work, metal $\left(\mathrm{Cu}^{2+}\right)$-substituted ninhydrin single crystals were grown by slow evaporation method. The grown crystals have been subjected to single crystal XRD, powder X-ray diffraction, FTIR, dielectric and SHG studies. Single crystal $\mathrm{X}$-ray diffraction analysis reveals that the compound crystallizes in monoclinic system with noncentrosymmetric space group P21 with lattice parameters $a=11.28 \AA, b=5.98 \AA, c=5.71 \AA, \alpha=90^{\circ}, \beta=98.57, \gamma=90^{\circ}$, and $V=381(\AA)^{3}$, which agrees very well with the reported value. The sharp and strong peaks in the powder X-ray diffraction pattern confirm the good crystallinity of the grown crystals. The presence of dopants marginally altered the lattice parameters without affecting the basic structure of the crystal. The UV-Vis transmittance spectrum shows that the crystal has a good optical transmittance in the entire visible region with lower cutoff wavelength $314 \mathrm{~nm}$. The vibrational frequencies of various functional groups in the crystals have been derived from FT-IR analysis. Based on the shifts in the vibrations, the presence of copper in the lattice of the grown crystal is clearly established from the pure ninhydrin crystals. Both dielectric constant and dielectric loss decrease with the increase in frequency. The second harmonic generation efficiency was measured by employing powder Kurtz method.

\section{Introduction}

The search for new materials with high optical nonlinearity is an important area due to their practical applications such as optical communication, optical computing, optical information processing, optical disk data storage, laser fusion reactions, laser remote sensing, colour display, medical diagnostics, and so forth [1-4]. In semiorganic materials, the organic ligand is ionically bonded with inorganic host. Due to this, the new semiorganic crystals have higher mechanical strength and chemical stability. Most of the organic NLO crystals usually have poor mechanical and thermal properties and are susceptible to damage during processing even though they have large NLO efficiency. Also it is difficult to grow larger size optical quality crystals of these materials for device applications. Purely inorganic NLO materials have excellent mechanical and thermal properties but possess relatively modest optical non linearity because of the lack of extended pi-electron delocalization.

Organic NLO materials are often superior to inorganic in terms of their response speed, optical clarity, and the magnitude of their third order susceptibility and for a material to exhibit NLO activity it should be noncentro symmetric. Hence it may be useful to prepare semiorganic crystals which combine the positive aspects of organic and inorganic materials resulting in useful non linear optical properties. Organic materials with aromatic rings having high non linear optical coefficient, higher laser damage threshold, fast response, low mobility, and large band gap find many applications [5-8].

Ninhydrin $\mathrm{C}_{9} \mathrm{H}_{6} \mathrm{O}_{4}$ (2,2-Dihydroxyindane-1,3-Dione) is one such organic materials with high melting point and two 
hydroxyl groups attached to the same carbon atom. It is used to detect ammonia or primary and secondary amines and fingerprints. It is also used in amino acid analysis of proteins. Ninhydrin molecules play a vital role in many fields like soil biology, chemistry, agriculture, medicine, forensic, food science, and so on. Also it is a potential material for micromolar determination of human serum albumin based on chemiluminescence and microbial activity [9]. Recently, Uma Devi et al. found the suitability of ninhydrin crystals for the nonlinear optical applications and found that second harmonic generation efficiency is five times that of KDP. Ninhydrin crystallizes in a noncentrosymmetric space group of $\mathrm{P} 2{ }_{1}$ and belongs to monoclinic system [10]. Uma Devi et al. already reported the growth and characterization of pure ninhydrin [11] and urea with ninhydrin [12] and stated that urea ninhydrin monohydrate crystal crystallizes in centro symmetric space group of $\mathrm{P} 21 / \mathrm{c}$. The addition of some transition metal ions is expected to influence the growth kinetics, habit modification, and the large-size single crystals. The presence of small amount of impurities such as $\mathrm{Ni}^{2+}$, $\mathrm{Cu}^{2+}$, and $\mathrm{Mg}^{2+}$ plays an important role in the growth rate, habit modification of the crystal, and its properties [13]. An impurity can suppress, enhance, or stop the growth of crystal completely. The impurity effect depends on the impurity concentration, super saturation, temperature, and $\mathrm{pH}$ of the solution and this can be successfully explained already for many NLO crystals [14]. In the present work, we report the growth of $\mathrm{Cu}^{2+}$-doped ninhydrin single crystals and studied the effect of $\mathrm{Cu}^{2+}$ in the system.

\section{Materials and Methods}

Single crystals of $\mathrm{Cu}^{2+}$ doped ninhydrin were grown by slow evaporation method. To the $100 \mathrm{~mL}$ saturated solution of ninhydrin, $0.2 \%$ of $\mathrm{CuCl}_{2}$ was added slowly and stirred well for nearly 2 hours, then filtered, and allowed to cool. Within 10 days tiny, pale yellow crystals of dimension $5.07 \mathrm{~mm} \times$ $3.41 \mathrm{~mm} \times 2.69 \mathrm{~mm}$ were harvested.

2.1. Characterization. The grown crystals have been subjected to various characterization studies like single crystal XRD, FT-IR, dielectric, and SHG. The grown crystals of the title compound were subjected to single crystal XRD analysis using ENRAF Nonius AD4/MAC4 X-ray diffractometer with $\mathrm{M}_{o} \mathrm{~K}_{\alpha}(\lambda=0.71073 \AA)$ radiation. The grown crystals have also been characterized by X-ray powder diffraction technique using Rich Seifert X-ray powder diffractometer with $\mathrm{CuK}_{\alpha}$ radiation of $\lambda=1.5406 \AA$. The $2 \theta$ range was analyzed from $10^{\circ}$ to $70^{\circ}$ by employing the reflection mode for scanning. The detector used was a scintillation counter. The UV-Visible spectrum of the grown crystal was recorded between 200 and $1200 \mathrm{~nm}$ using CARY/5E/UV spectrophotometer. A Perkin Elmer Spectrum one FT-IR spectrometer was employed to record the IR spectrum to analyze the functional groups present in the crystals. The sample for this measurement was finely grounded and mixed with $\mathrm{KBr}$. The dielectric study was carried out using the instrument, HIOKI model 3532-50 LCR HITESTER. Samples of known

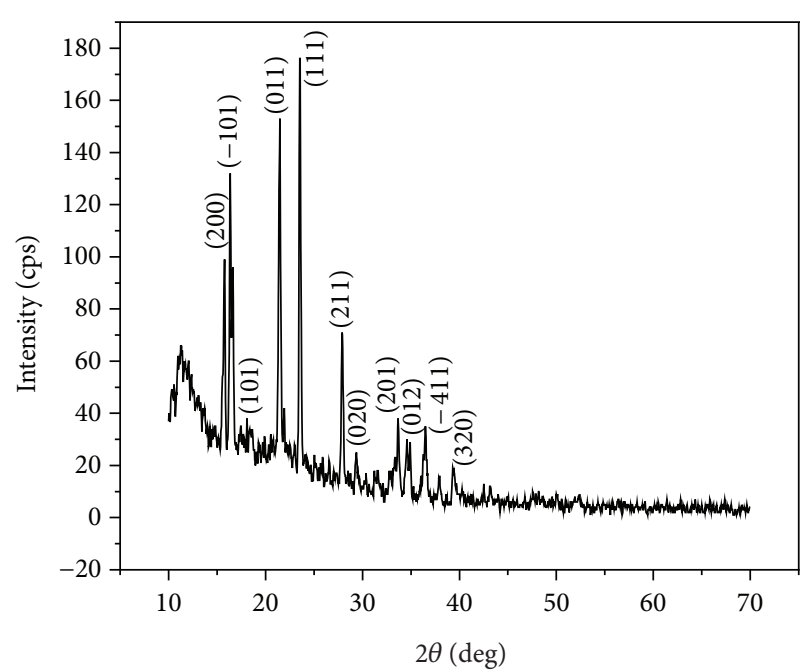

FIgURE 1: Indexed X-ray powder diffraction pattern $\mathrm{Cu}^{2+}$ doped ninhydrin.

dimension $(5.07 \mathrm{~mm} \times 3.41 \mathrm{~mm} \times 2.69 \mathrm{~mm})$ were silver coated on the opposite faces and then placed between the two copper electrodes to form the parallel plate capacitor. The capacitance of the sample was noted for the applied frequency that varies from $100 \mathrm{~Hz}$ to $5 \mathrm{MHz}$ at different temperatures $(353 \mathrm{~K}$ and $373 \mathrm{~K})$. The grown crystals of ninhydrin were subjected to Kurtz second harmonic generation test by using Nd:YAG Q switched laser beam with input pulse of $0.68 \mathrm{~J}$ for the non linear optical property.

\section{Results and Discussion}

3.1. Single Crystal XRD. The single crystal XRD data of the title crystal indicates that it crystallizes in the monoclinic system with noncentrosymmetric space group $\mathrm{P} 2{ }_{1}$ with lattice parameters $a=11.28 \AA, b=5.98 \AA, c=5.71 \AA, \alpha=$ $90^{\circ}, \beta=98.57, \gamma=90^{\circ}$, and $V=381(\AA)^{3}$, which agrees very well with the reported value [10]. It is observed that there is a slight change in unit cell parameters which reflects the lattice distortion due to the substitution of $\mathrm{Cu}^{2+}[15]$.

3.2. Powder X-Ray Diffraction Analysis. The crystal structure of ninhydrin was reported by Medrud [10]. The title crystal crystallizes in monoclinic with space group $\mathrm{P} 2{ }_{1}$. Figure 1 shows the indexed X-ray powder diffraction pattern of the grown title crystal. The results agree well with XRD pattern of ninhydrin molecule [11]. Appearance of sharp and strong peaks confirms the good crystallinity of the grown crystals. The prominent peaks have been indexed. A small change in the intensity level of the peaks and peak position at the higher angle side is due to the addition of copper.

3.3. Optical Transmission Spectral Analysis. The UV-Vis spectrum gives information about the structure of the molecule that the absorption of UV and visible light involves in the promotion of electrons in $\sigma$ and $\pi$ orbital from the ground 


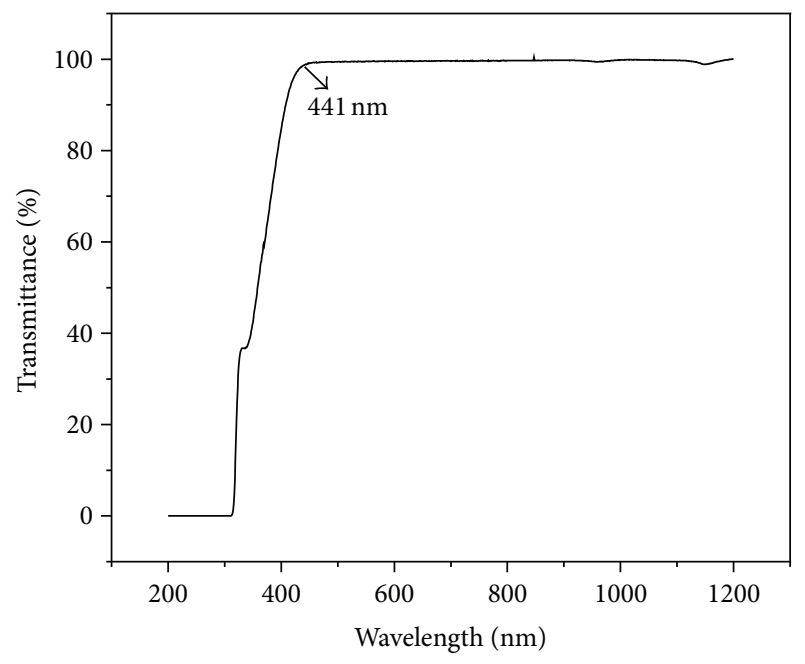

FIGURE 2: Optical transmission spectrum $\mathrm{Cu}^{2+}$ doped ninhydrin.

state to higher energy state. The UV transmission spectrum of grown crystal is shown in Figure 2. The determination of UV transparency and cutoff wavelength is very important since these crystals are mainly used in optical application. The lower cut off wavelength is found to be $314 \mathrm{~nm}$ and upper cut off wavelength is $441 \mathrm{~nm}$. Between 450 and $1200 \mathrm{~nm}$, there is no absorption of wavelength which clearly indicates that grown crystals can be used as window material in optical instruments. The small peak at $339 \mathrm{~nm}$ is due to $\mathrm{n}-\pi^{*}$ transition [16]. High transmittance \% observed from $450 \mathrm{~nm}$ indicates that the crystal possesses good optical transparency for SHG of Nd:YAG laser.

3.4. FTIR Analysis. Fourier Infrared spectrum was recorded using $\mathrm{KBr}$ pellet technique in the range $400-4000 \mathrm{~cm}^{-1}$ and the recorded FTIR spectrum is shown in Figure 3. Vibrational spectroscopy provides an important tool to understand the chemical bonding.

The strong absorption peak at $3298 \mathrm{~cm}^{-1}$ is due to $\mathrm{O}-\mathrm{H}$ symmetric stretching [12] and $3087 \mathrm{~cm}^{-1}$ is due to aromatic $\mathrm{C}-\mathrm{H}$ stretching. The carbonyl $(\mathrm{C}=\mathrm{O})$ peak is observed at $1747 \mathrm{~cm}^{-1}$ and $1717 \mathrm{~cm}^{-1}$. A medium intense peak observed at $1592 \mathrm{~cm}^{-1}$ is attributed to aromatic ring vibration [17]. Peaks at $1292 \mathrm{~cm}^{-1}$ and $741 \mathrm{~cm}^{-1}$ are attributed to in-plane bending modes of aromatic $\mathrm{C}-\mathrm{H}$ bonding and out-of-plane aromatic $\mathrm{C}-\mathrm{H}$ bonding, respectively [18]. The peaks at $1063 \mathrm{~cm}^{-1}, 1153 \mathrm{~cm}^{-1}, 1186 \mathrm{~cm}^{-1}, 1255 \mathrm{~cm}^{-1}$, and $1292 \mathrm{~cm}^{-1}$ are attributed to the plane bending modes of aromatic $\mathrm{C}-\mathrm{H}$ bonds.

3.5. Dielectric Studies. The dielectric properties are associated with the electro-optic property of materials, particularly when they are nonconducting materials [19]. Microelectronics industry needs low $\varepsilon_{r}$ materials as an interlayer dielectric. Figures 4 and 5 show the variations of dielectric constant and dielectric loss of the title crystal at two different temperatures, that is, $353 \mathrm{~K}$ and $373 \mathrm{~K}$, as a function of frequency.

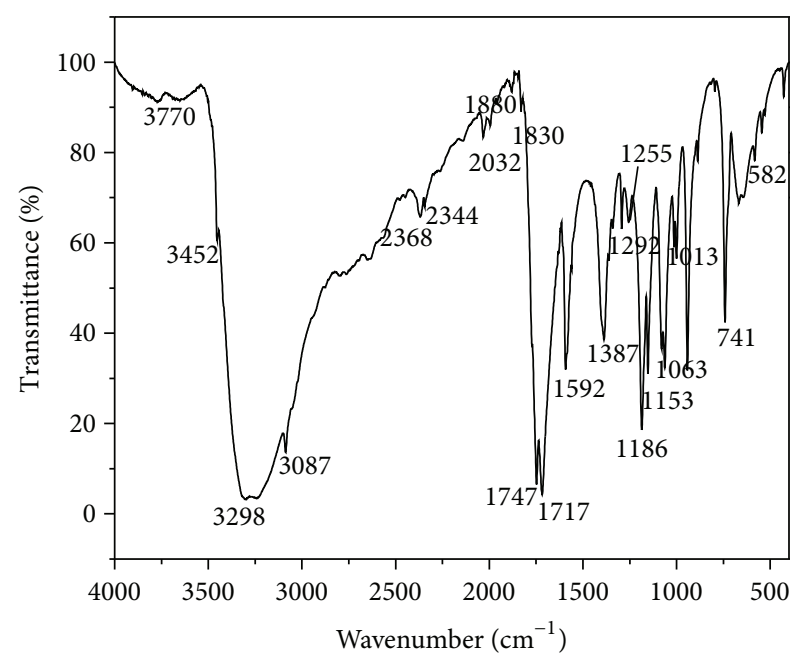

FIGURE 3: FTIR spectrum of $\mathrm{Cu}^{2+}$ doped ninhydrin.

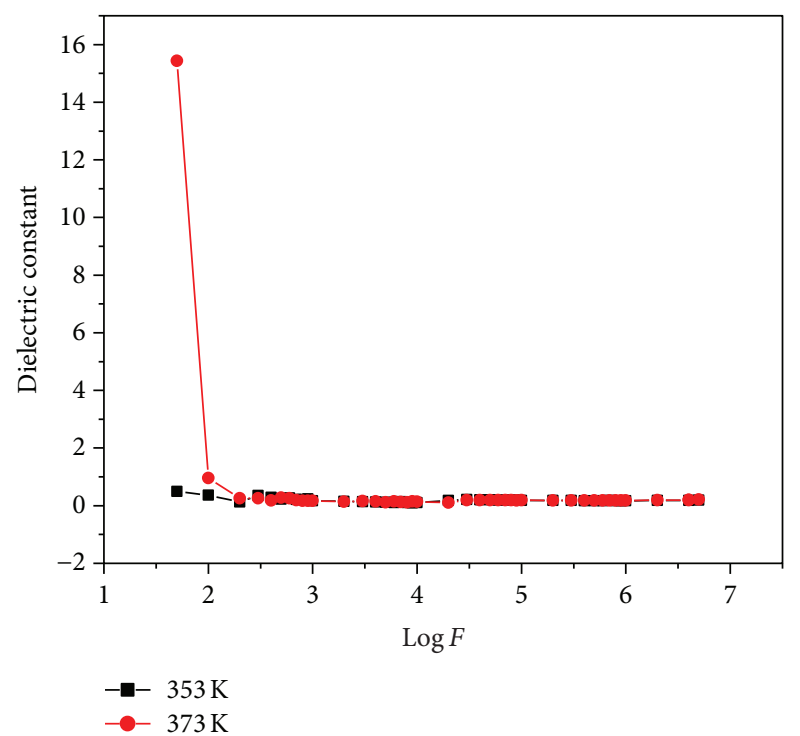

FIGURE 4: Variation of Dielectric constant with frequency for different temperatures.

The dielectric constant is calculated using the formula

$$
\varepsilon^{\prime}=\frac{C t}{\varepsilon_{o} A}
$$

where $C$ is capacitance (farad), $t$ is the thickness (metre), $A$ the area $\left(\mathrm{m}^{2}\right), \varepsilon_{o}$ is the absolute permittivity in the free space having a value of $8.854 \times 10^{-12} \mathrm{Fm}^{-1}$.

It is seen that the value of dielectric constant is found to decrease and attain constant values in the higher frequency region. The decrease in dielectric constant of the title crystal at low frequencies may be attributed to the contribution of the electronic, ionic, orientation, and space charge polarizations which depend on the frequencies. At low frequencies all the four contributions are active [20]. The low value of $\varepsilon_{r}$ at 


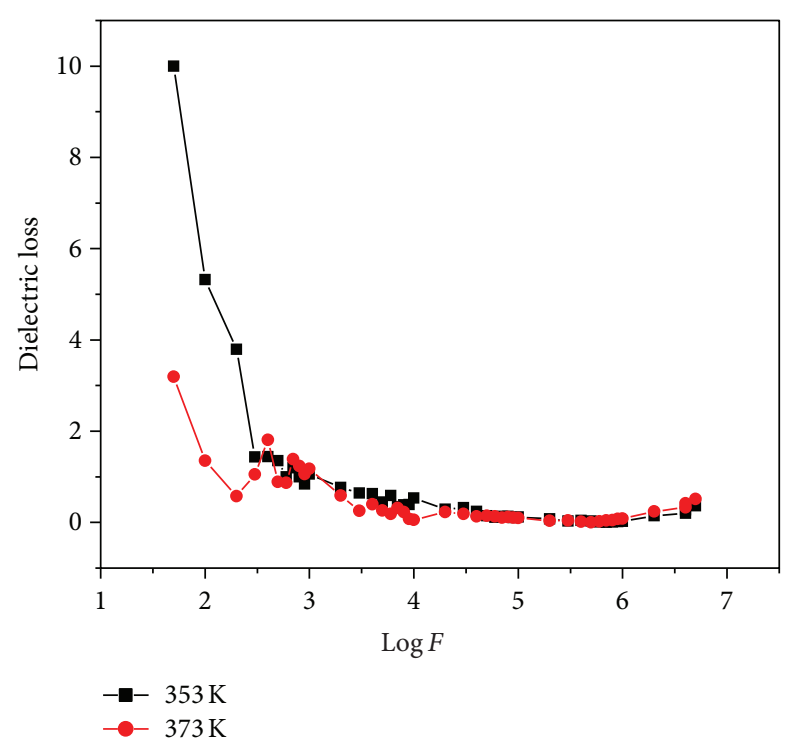

FIGURE 5: Variation of dielectric loss with frequency for different temperatures.

high frequencies are important for these materials in the construction of photonic and NLO devices which suggests that the sample possesses enhanced optical quality with low level defects [20-22]. Dielectric loss decreases with increase in frequency. The larger value of $\varepsilon_{r}$ and $\tan \delta$ at low frequency arises due to the presence of space charge polarization near the grain boundary interfaces which depends on the purity and perfection of the sample [22].

3.6. SHG Test. Second harmonic generation test was performed to find the NLO property of the grown crystal by using Kurtz-Perry technique [23]. Nd:YAG laser using the first harmonics output of $1064 \mathrm{~nm}$ with pulse width of $8 \mathrm{~ns}$ and repletion rate $10 \mathrm{~Hz}$ was passed through the sample. The green signal was emitted which confirms the second harmonic generation efficiency.

\section{Conclusion}

Single crystals of $\mathrm{Cu}^{2+}$ doped ninhydrin were grown by slow solvent evaporation technique. Single crystal XRD confirmed the unit cell parameters with the reported value. In powder Xray diffraction pattern, appearance of sharp and strong peaks confirms the good crystallinity of the grown crystals also the prominent of peaks has been indexed. UV-Vis-NIR study reveals the suitability of the crystal for NLO applications and the lower cut off wavelength is found to be $314 \mathrm{~nm}$ and upper cut off wavelength is $441 \mathrm{~nm}$. There is no absorption of wavelength in the entire visible region. FT-IR spectrum gives the various functional groups present in the structure. A medium intense peak observed at $1592 \mathrm{~cm}^{-1}$ is attributed to aromatic ring vibration. The carbonyl $(\mathrm{C}=\mathrm{O})$ peak is observed at $1747 \mathrm{~cm}^{-1}$ and $1717 \mathrm{~cm}^{-1}$. The other stretching modes have also been assigned. From the dielectric study, it is found that both dielectric constant and dielectric loss of the crystal decrease with increase in frequency. The emission of green signal confirms the second harmonic generation efficiency of the crystal. Thus, the moderate SHG efficiency and encouraging dielectric properties of the crystal indicate the suitability of this crystal for photonic device fabrication.

\section{References}

[1] S. Chenthamarai, D. Jayaraman, C. Subramanian, and P. Ramasamy, "Mechanical and optical studies on pure and nitro doped 4-hydroxyacetophenone," Materials Letters, vol. 47, no. 4-5, pp. 247-251, 2001.

[2] N. P. Rajesh, V. Kannan, P. S. Raghavan, P. Ramasamy, and C. W. Lan, "Optical and microhardness studies of KDP crystals grown from aqueous solutions with organic additives," Materials Letters, vol. 52, no. 4-5, pp. 326-328, 2002.

[3] Z. G. Hu, M. Yoshimura, Y. Mori, and T. Sasaki, "Growth and characterization of a novel NLO crystal bis-glycine hydrogen chloride (BGHC)," Journal of Crystal Growth, vol. 286, no. 2, pp. 440-444, 2006.

[4] S. S. Hussaini, N. R. Dhumane, G. Rabbani, P. Karmuse, V. G. Dongre, and M. D. Shirsat, "Growth and high frequency dielectric study of pure and thiourea doped KDP crystals," Crystal Research and Technology, vol. 42, no. 11, pp. 1110-1116, 2007.

[5] C. K. Lakshmana Perumal, A. Arulchakkaravarthi, N. P. Rajesh et al., "Synthesis, crystal growth and FTIR, NMR, SHG studies of 4-methoxy benzaldehyde-N-methyl-4-stilbazolium tosylate (MBST)," Journal of Crystal Growth, vol. 240, no. 1-2, pp. 212-217, 2002.

[6] C. W. . Tang and S. A. Vanslyke, "Organic electroluminescent diodes," Applied Physics Letters, vol. 51, no. 12, pp. 913-915, 1987.

[7] L. R. Dalton, "Organic electro-optic materials," Pure and Applied Chemistry, vol. 76, no. 7-8, pp. 1421-1433, 2004.

[8] K. Jaganathan, S. Kalainathan, T. Gnasekaran, N. Vijayan, and G. Bhagavanarayan, "Growth and characterization of a novel organic NLO crystal: 4-ethoxy benzaldehyde-n-methyl 4-stilbazolium tosylate," Crystal Research and Technology, vol. 42, no. 5, pp. 483-487, 2007.

[9] N. S. R. R. M. M. Koteswar Rao and M. G. Ram Reddy, "Studies on the synthesis, characterisation and antimicrobial activity of new $\mathrm{Co}(\mathrm{II}), \mathrm{Ni}(\mathrm{II})$ and $\mathrm{Zn}$ (II) complexes of Schiff base derived from ninhydrin and glycine," Biometals, vol. 3, no. 1, pp. 19-23, 1990.

[10] R. C. Medrud, “The crystal structure of ninhydrin," Acta Crystallographica B, vol. 25, no. 2, pp. 213-220, 1969.

[11] T. Uma Devi, N. Lawrence, R. Ramesh Babu, K. Ramamurthi, and G. Bhagavannarayana, "Growth of ninhydrin single crystal and its characterization," Spectrochimica Acta A, vol. 71, no. 5, pp. 1667-1672, 2009.

[12] T. Uma Devi, N. Lawrence, R. Ramesh Babu, S. Selvanayagam, H. Stoeckli-Evans, and K. Ramamurthi, "Characterization of a newly synthesized organic nonlinear optical crystal: urea ninhydrin monohydrate," Journal of Crystal Growth, vol. 311, no. 13, pp. 3485-3490, 2009.

[13] V. G. Dmitriev, G. G. Gurzadyan, and D. N. Nikogosyan, Handbook of Non Linear Optical Crystals, Springer, Berlin, Germany, 3rd edition, 1999. 
[14] K. Sangwal and K. W. Benz, "Impurity striations in crystals," Progress in Crystal Growth and Characterization of Materials, vol. 32, no. 1-3, pp. 135-169, 1996.

[15] D. Suryanarayana and J. Sobhanadri, "ESR studies of $\mathrm{Cu}^{2+}$ doped in $\mathrm{Na}_{2} \mathrm{SO}_{4}$ single crystals," Journal of Magnetic Resonance, vol. 14, no. 1, pp. 1-12, 1974.

[16] W. Kemp, Organic Spectroscopy, Palgrave Macmillan, 1991.

[17] R. J. Dyer, Applications of Absorption Spectroscopy of Organic Compounds, Prentice Hall, New Delhi, India, 1994.

[18] K. Biemann, Tables of Spectral Data for Structure Determination of Organic Compounds, Springer, Berlin, Germany, 1989.

[19] S. Boomadevi, H. P. Mittal, and R. Dhansekaran, "Synthesis, crystal growth and characterization of 3-methyl 4-nitropyridine 1-oxide (POM) single crystals," Journal of Crystal Growth, vol. 261, no. 1, pp. 55-62, 2004.

[20] K. V. Rao and A. Samakula, "Dielectric properties of cobalt oxide, nickel oxide, and their mixed crystals," Journal of Applied Physics, vol. 36, no. 6, pp. 2031-2038, 1965.

[21] B. D. Hatton, K. Landskron, W. J. Hunks et al., "Materials chemistry for low-k materials," Materials Today, vol. 9, no. 3, pp. 22-31, 2006.

[22] S. Suresh, A. Ramanand, D. Jayaraman, and P. Mani, "Growth, photoconductivity and dielectric properties of triglycine sulfate (TGS) single crystals," Optoelectronics and Advanced Materials, Rapid Communications, vol. 4, no. 11, pp. 1763-1765, 2010.

[23] S. K. Kurtz and T. T. Perry, "A powder technique for the evaluation of nonlinear optical materials," Journal of Applied Physics, vol. 39, no. 8, pp. 3798-3813, 1968. 

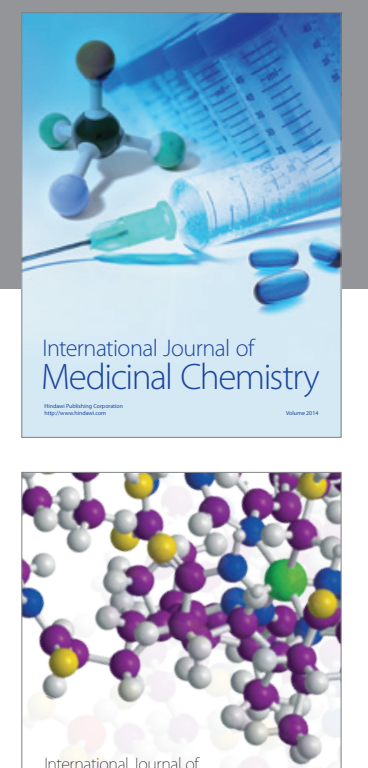

\section{Carbohydrate} Chemistry

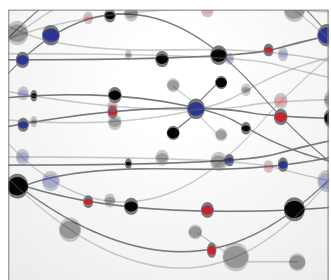

The Scientific World Journal
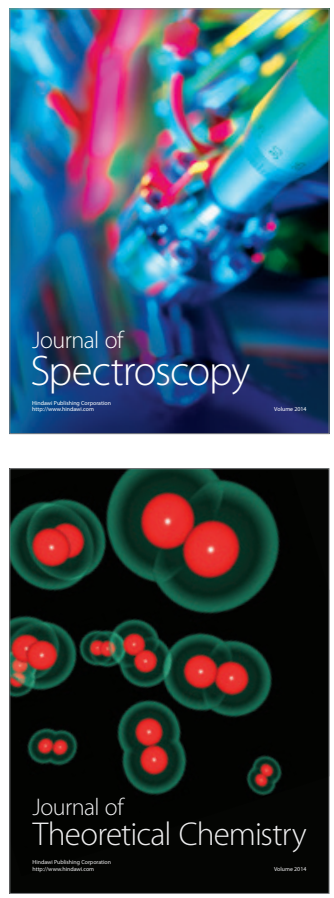
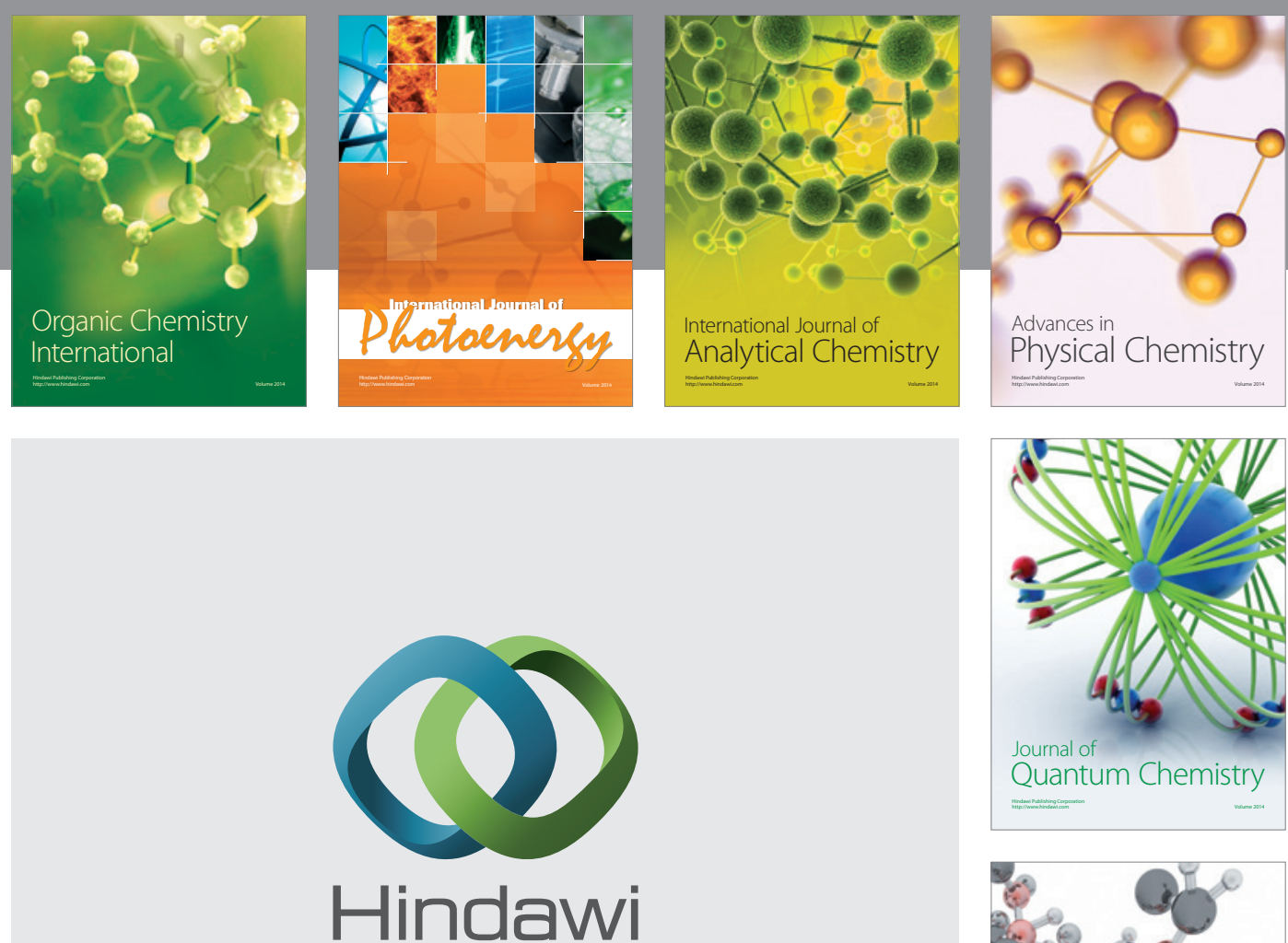

Submit your manuscripts at

http://www.hindawi.com

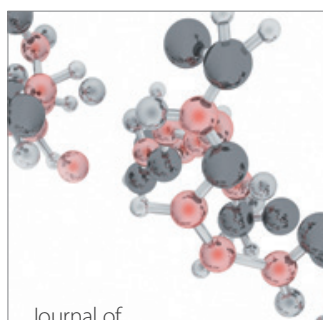

Analytical Methods

in Chemistry

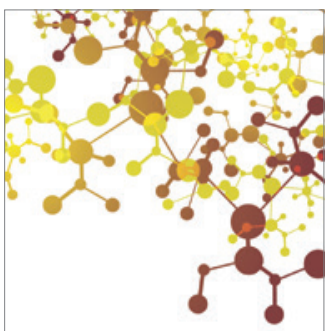

Journal of

Applied Chemistry

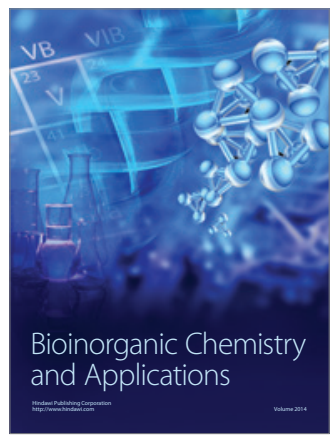

Inorganic Chemistry
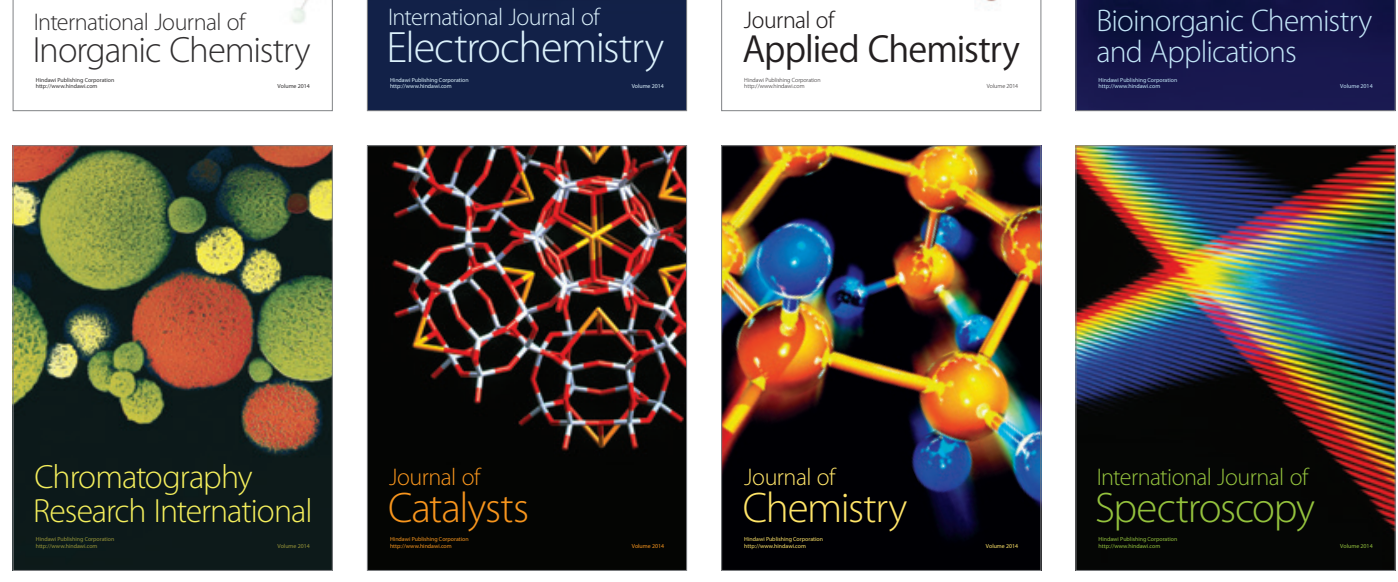